\title{
THE PROBLEMS, RHETORICAL AND GRAMMATICAL, IN THE TEACHING OF THAT AND WHICH IN NONRESTRICTIVE AND RESTRICTIVE ADJECTIVAL CLAUSES
}

\author{
Juan Carlos Vargas \\ Marco Flores
}

\begin{abstract}
RESUMEN
El uso de that y which en oraciones subordinadas adjetivas de carácter restrictivo en inglés ha sido definido, durante mucho tiempo, por los profesores de gramática y composición — that y which son intercambiables en dichas oraciones. Sin embargo, algunos de los más connotados gramáticos y teóricos del idioma inglés afirman que that y which no deberían emplearse indistintamente. Expertos tales como W. H. Fowler, Theodore Bernstein y Fredrick Crews, en contraste con la práctica común para el uso de estas palabras, recomiendan que that sea empleado exclusivamente para oraciones restrictivas y which para oraciones no restrictivas. En este artículo se revisa, analiza y evalúa un debate que ha sido ignorado en libros de texto y de referencia empleados en la enseñanza del inglés.
\end{abstract}

\section{ABSTRACT}

The use of that and which in adjectival restrictive clauses has long been defined by teachers of grammar and composition: that and which are interchangeable in such clauses. However, some of the most distinguished grammarians and theoreticians of English usage claim that that and which should not be used interchangeably. No less experts than W.H. Fowler, Theodore Bernstein, and Fredrick Crews, in stark contrast to the accepted classroom decorum for these words, recommend strongly that that be used exclusively for restrictive clauses and which for nonrestrictive ones. This debate, largely ignoreed in the texts and referencebooks used for instruction, is reviewed, analyzed, and assessed in this article.

The teaching of that and which in nonrestrictive and restrictive adjectival clauses is a long and complicated history. Among grammarians and rhetoric teachers, there seems to be little debate about whether that or which should be used in nonrestrictive clauses. Indeed nothing is more emphatically uniform on the part of grammarians than the insistence that only which be used in nonrestrictive clauses. On this issue, consensus is not only clear but overwhelming, and one would reveal oneself to be grammatically and rhetorically illiterate by arguing the reverse of what has been a long-established rule. All nonrestrictive clauses must begin with which, and this rule is nowhere more manifestly stated than in Fredrick Crews's The Random House Handbook. We quote textually from the section on the use of that and which in nonrestrictive clauses:

- A nonrestrictive clause is one that comments on an antecedent instead of identifying it. Nonrestrictive clauses can be introduced by which but never that:

- A more specific reason, which the manager didn't mention to Melody, was that she always asked the costumers for spare change. (Crews 1974: 184) 
Crews then explains what has already been clearly stated above: "Which the manager didn't mention to Melody is a nonrestrictive clause, since it doesn't serve to identify its antecedent reason. Note how the commas convey the nonrestrictive sense [...] the sentence would be incorrect if which were replaced by that" (Crews 184). The rule, and Crews's commentary on the rule, cannot be any more categorical: Which should never be substituted by that in nonrestrictive clauses. We need not cite many more examples to prove this point. Even a cursory examination of any grammar or rhetoric book will validate the importance and universality of this long-standing rule. Here is C.T. Onions, one of the editors of the Oxford English Dictionary, and author of An Advanced English Syntax: Based on the Principles and Requirements of the Grammatical Society, on the issue of that and which in restrictive and nonrestrictive adjectival clauses. It is worth quoting C.T. Onions entire:

Relative clauses may be used for two purposes-

(a) to help to limit or define more clearly the antecedent, which without the Relative Clause would in some cases make no sense, and in others convey quite a different sense from that intended:

This is the house that Jack built.

Uneasy lies the head that wears a crown.

In such cases the Relative Clause is introduced by that, except after preposition or where whose is required; no comma is used to separate the Relative Clause from its Antecedent; and the Relative may be omitted in the usual way...

(b) to give some additional information about an antecedent which is already sufficiently defined:

A brother of his, who has a candle factory, is rolling in riches.

These books, which are only a small part of my collection, I picked up in France.

I gave him a shilling, which is all I had with me.

In such cases the Relative Clause must be introduced by who (whom), which; a comma separates a Relative from its Antecedent, and the Relative cannot be omitted. (Onions 1965: 72)

As to nonrestrictive clauses, C.T. Onions writes that the "Relative Clause must be introduced by who (whom), which." The verb used by Onions is "must." There is no wiggle room here, and once again this long-standing rule has been affirmed.

As we all know, restrictive clauses (which are also called "defining" or "limitative") help define the antecedent, while nonrestrictive clauses (which are also called "nondefining" or "parenthetical") add "information about an antecedent which is already sufficiently defined." This is the standard definition for the two terms. And, of course, commas help separate out the nonrestrictive clause, while no such commas are used with a restrictive clause. In Abusage \& Usage, Eric Partridge enumerates the difference between the two clauses as such:

A useful rule—at least $I$ have found it useful—is this of mine: the restrictive or defining or limitative or necessary relative clause ... forms an integral, irremovable part of a sentence and cannot be put within parentheses, whereas the non-restrictive relatives... can always be put within parentheses and their omission would not render the sentence senseless. (Partridge 1947: 365) 
Here Partridge offers us the standard way to teach students the difference between the two clauses. He stresses, as do most teachers, the parenthetical nature of nonrestrictive clauses; as with a surgical instrument, they can be lifted out of the waters without ruffling the surface at all.

But matters get far more complicated when we turn our attention to restrictive clauses and the appropriate use therein of which or that. Indeed the issue becomes cloudy and murky, filled with varying levels of ambiguity and confusion. Are that and which interchangeable in restrictive clauses? It seems that a whole host of grammarians and rhetoric teachers seem to think that they are unhesitatingly interchangeable.

In Practical English Handbook, Watkins and Dillingham, for example, cite the following two sentences as examples for restrictive clauses:

- Huge signs which are displayed along interstate highways spoil the beauty of the countryside.

- Words which convey images are important in poetry. (Watkins 1986: 123)

Watkins and Dillingham emphasize that in "these sentences, the italicized expressions identify the words they modify: to remove the modifiers would be to change the meaning" (Watkins 123). But the point is that these two writers clearly believe that, in restrictive clauses, a writer may use either which or that to introduce the adjectival relative clause. Although never explicitly said, it is important to note that in the two examples above of restrictive adjectival clauses, it is which that serves to introduce the clause. Hence, one can clearly deduce that they accept the use of which as frequently in restrictive clauses as that. Watkins and Dillingham then cite more examples of restrictive clauses introduced by which:

- $\quad$ The name Rover was often associated with dogs which were happy.

- Americans who have grown up in the prairies may feel shut in when they move to forest regions or to cities with buildings which have more than ten stories.

- Courses which are not challenging usually do not instruct the students who have the best minds.

Similarly, in Jan Frodesen and Janet Eyring's Grammar Dimensions, the point concerning the interchangeability of that and which in adjectival restrictive clauses is stated outright, and the students are instructed to use either one or the other discretionally. They offer the students an orderly chart for their edification and instruction concerning the usage of that and which: 


\begin{tabular}{llll}
\hline Examples & $\begin{array}{l}\text { Object } \\
\text { Being } \\
\text { Modified }\end{array}$ & $\begin{array}{l}\text { Relative } \\
\text { Pronoun }\end{array}$ & $\begin{array}{l}\text { Function } \\
\text { Of } \\
\text { Relative Pronoun }\end{array}$ \\
\hline $\begin{array}{l}\text { I have noticed the trash that / } \\
\text { which is piled on the street. }\end{array}$ & $\begin{array}{l}\text { thing or } \\
\text { animal }\end{array}$ & that/which & subject \\
$\begin{array}{l}\text { Did you see the apartment that / } \\
\text { which he furnished himself? }\end{array}$ & that/which & direct object \\
$\begin{array}{l}\text { He patted the dog that / which } \\
\text { he had given a home to. }\end{array}$ & that/which & indirect object \\
$\begin{array}{l}\text { Toronto has a tall tower that / } \\
\text { which you can get a great. } \\
\text { view from. }\end{array}$ & that/which & $\begin{array}{l}\text { object of a } \\
\text { preposition }\end{array}$ \\
& & (Frodesen 1994: 131) \\
\hline
\end{tabular}

Referring only to restrictive clauses, Frodesen and Eyring make their point again about the interchangeability of that and which specifically in restrictive clauses:

\begin{tabular}{llll}
\hline Examples & $\begin{array}{l}\text { Subject } \\
\text { Being } \\
\text { Modified }\end{array}$ & $\begin{array}{l}\text { Relative } \\
\text { Pronoun }\end{array}$ & $\begin{array}{l}\text { Function } \\
\text { Of } \\
\text { Relative Pronoun }\end{array}$ \\
\hline $\begin{array}{l}\text { The mansions that / which } \\
\text { were sold last week were } \\
\text { expensive. }\end{array}$ & $\begin{array}{l}\text { thing or } \\
\text { animal }\end{array}$ & that/which & subject \\
$\begin{array}{l}\text { The computer that / which } \\
\text { they purchased operated } \\
\text { very efficiently. }\end{array}$ & that/which & direct object \\
$\begin{array}{l}\text { The place that / which you } \\
\text { spoke about is Denver. }\end{array}$ & that/which & $\begin{array}{l}\text { object of a } \\
\text { preposition }\end{array}$ \\
& & (Frodesen 1994: 120)
\end{tabular}

Here the point cannot be more emphatic. Frodesen and Eyring instruct students to use either that or which in adjectival restrictive clauses.

Similarly, in Understanding and Using English Grammar, Betty Azar cites the following examples:

- The book which is on the table is mine.

- The book that is on the table is mine. (Azar 238) 
And shortly thereafter Azar cites two more examples of how that and which are interchangeable:

- $\quad$ The movie which we saw last night wasn't very good.
- $\quad$ The movie that we saw last night wasn't very good. (Azar 1989: 239)

In an Index To Modern English, Thomas L. Crowel states in regards to restrictive clauses that "either a $\boldsymbol{w h}$ word or that may be used, or the relative word may be omitted. No commas are needed" (Crowel 1964: 90). He goes on to cite the following example of the interchangeability of that and which and of the possible and grammatically permitted omission altogether of the relative pronoun that functions as an object:

I am reading a book which I like very much.

that I like very much.

I like very much. (Crowel 1964: 90)

We could go on endlessly with examples from grammar books concerning the use of which and that. Note that, in all the examples, cited above not one grammarian even remotely suggests that there is any dispute about this issue. Indeed, grammarians seem to walk in lockstep on this matter. That and which are interchangeable, and this rule is taken apparently for granted in all of the cited grammar textbooks above.

But if we return to Fredrick Crews's Random House Handbook, we find that he holds the reverse position, a position in regards to that and which that seems to bear witness to the fact that these two words, however much they might look like twins to many grammarians, bear little resemblance to one another in the mind of this distinguished rhetoric teacher in restrictive clauses:

Some writers, recognizing that which and that aren't interchangeable in nonrestrictive clauses, prefer to use only that in restrictive clauses [...] Although this distinction isn't strictly required for correctness, it has the advantage of always serving notice when a clause is going to be restrictive. No harm can come from holding yourself to this 'rule': that for restrictive, which for nonrestrictive clauses. (Crews 1974: 184)

Crews places "rule" within quotation marks precisely because it is not a rule. But he clearly and indisputably would like to see such a rule established and, indeed, however invisible the rule might presently be, he seems more than willing to acknowledge its existence: "No harm can come from holding yourself to this 'rule': that for restrictive, which for nonrestrictive clauses."

In The Careful Writer: A Modern Guide to English Usage, Theodore M. Bernstein, a consulting editor for The New York Times, makes a similar point: "What kinds of clauses are 'properly' begun with that and what kinds with which? That is better used to introduce a limiting or defining clause, which to introduce a nondefining or parenthetical clause" (Bernstein 443). The point had already been made by Crews; the positions of Crews and Bernstein are identical on this issue of the usage of that and which in restrictive clauses, and yet they differ from the positions stated above by Watkins and Dillingham, Frodesen and Eyring, Crowel, and Azar, all of whom stress the unquestionable interchangeability of that and which in restrictive adjectival clauses. 
In The Careful Writer, Bernstein begins by disabusing us of the all-too-common notion about that being used principally in conversation and which in written language:

\begin{abstract}
There are writers who have the notion that the relative that is colloquial(which it is in the sense that it is natural in spoken language), whereas the relative which is literary. That is a mistaken idea. Jespersen has put his finger on one cause of the error: 'Who and which reminded scholars of the Latin pronouns and came to be looked upon as more refined or dignified than the more popular that.' To this day there are those who seem to feel that which is more stately. (Bernstein 1981: 443)
\end{abstract}

He then goes on to cite W.H. Fowler on the fact that thats are used more frequently in the spoken word than whichs:

Fowler has identified another cause of the error: 'It is a fact that the proportion of thats to whichs is far higher in speech than in writing; but the reason is not that the spoken thats are properly converted into written whichs, but that the kind of clause properly begun with which is rare in speech with its short detached sentences, but very common in the more complex \& continuous structure of writing, while the kind properly begun with that is equally necessary in both'. (Bernstein 1981: 443).

It is clear that for Bernstein, that and which should not be interchangeable in restrictive clauses.

In An Advanced English Syntax: Based on the Principles and Requirements of the Grammatical Society, C.T. Onions, whom we cited above, makes the same point:

Relative clauses may be used for two purposes-

(a) to help to limit or define more clearly the antecedent, which without the Relative Clause would in some cases make no sense, and in others convey quite a different sense from that intended:

This is the house that Jack built.

Uneasy lies the head that wears a crown.

In such cases the Relative Clause is introduced by that, except after preposition or where whose is required; no comma is used to separate the Relative Clause from its Antecedent; and the Relative may be omittedin the usual way ... (Onions 1965: 72)

Onions writes above that the "Relative Clause is introduced by that." He does not even contemplate the use of which in restrictive clauses. There is no wiggle room here. ${ }^{1}$

If there is one voice in English that has for nearly eighty years offered insight into the usage of English, it is W. H. Fowler's. His monumental Dictionary of Modern English Usage has remained the staple for signaling infelicities of style in English prose since its publication in 1926. Not many voices have had more authority; no one has remained more revered down through the years than Fowler. On the issue of the use of that or which in adjectival relative clauses, Fowler has no apparent hesitancy or doubt: "if writers would agree to regard that as the defining relative pronoun, and which as the non-defining, there would be much gain both in lucidity and in ease" (Fowler 1977: 626).

Why does Fowler wish for the use of only that in restrictive clauses? The arguments for this position are based fundamentally on usage, and there is, as we have clearly seen, no rule per se, at least not that we can find, that stipulates that that would be in all circumstances 
a better alternative to which in all adjectival restrictive clauses. But there has been a great deal of ink spilt on behalf of that as the sole proprietor of restrictive clauses. And that there is a great deal of linguistic favoritism, and a longing for the use of that in restrictive adjectival clauses, is indisputable. Bernstein expresses best the position of those favoring the exclusive use of that for restrictive clauses, never which, and those favoring the exclusive use of which for nonrestrictive clauses:

\footnotetext{
Nowadays the use of that to introduce a nondefining or parenthetical clause is quite uncommon; we would not be likely to write: 'Hollywood, that has been the film center of the world, is being challenged by foreign studios." Which, however, as has been noted, appears not infrequently to introduce defining clauses, where that would be more natural: I found myself wondering what was the quality in him which interested me. (Bernstein 1981: 444)
}

Bernstein then cavalierly states: "Neither of these improper uses can be condemned on the ground of ambiguity; the meaning in each instance is perfectly clear." Like all of us, he reaffirms the use of which to that in the nonrestrictive clause cited above, but he obviously prefers that to which in the restrictive one.

Bernstein then goes on to cite examples where interchangeability of that and which in restrictive clauses might, to his mind, produce unwanted ambiguity and confusion:

- The New York Public Library will arrange for the disposal of the above books, which have no net salvage value, by destruction, by removal . . . .

- Although management will pay for deductions each month employe [sic] will receive a bill from the management for those deductions which must be paid in dollars.

- There are many different degrees of standard usage which cannot be distinguished by status labels. (Bernstein 1981: 444-5)

Bernstein argues that the first instance is confusing. Is the New York Public Library suggesting that all the books set for disposal have "no net salvage value" or will the library dispose of only those books that have no salvage value? But in this example the confusion results from not knowing whether one is writing a restrictive or a nonrestrictive clause. The confusion here is in the writer's mind, a result of not understanding what is intended, not the result of any confusion over the use of that or which. Which of the two meanings did the Public Library of New York wish to convey? In the end, Bernstein informs us, they meant to use a parenthetical statement, which is how the sentence is written above. As written, it is a nonrestrictive clause, and there is no confusion as far as we are concerned.

In the second example, we get closer to the issue at hand. Here, according to Bernstein, the use of which makes the sentence potentially confusing. Will employees receive a bill for deductions that must be paid in dollars? Or will each employee receive a bill from management about only those deductions that must be paid in dollars? Bernstein argues that in this sentence it would be far better to use that than which, and that this confusion would be immediately clarified if such were the case: "The latter was the intended meaning, and that instead of which would have made it instantly clear." We see, however, no lifting of confusion by using that instead of which in the above sentence unless Bernstein means to say that the use of that will make the clause modify deductions, by virtue of proximity, as a closer referent, than modify the word bill, which stands as a more distant 
neighbor. Bernstein would have the sentence read: "Although management will pay for deductions each month employe [sic] will receive a bill from the management for those deductions [that] must be paid in dollars." But is there any real difference in the meaning of the sentence by switching that for which? For us, the problem here is the potentially double antecedent for the relative clause (i.e., deductions and bill), not a question of the choice of the relative pronoun.

In the final example (There are many different degrees of standard usage which cannot be distinguished by status labels), Bernstein claims that "the absence of the comma suggests the editor meant the clause to be restrictive. But can one be sure? And would not the use of that have made it certain?" His point is well taken. The sentence might well have been written differently: "There are many different degrees of standard usage [that] cannot be distinguished by status labels" (Bernstein 445). And, to be sure, the issue of a restrictive or nonrestrictive clause would also, as in the preceding example, have been clarified immediately, especially for those writers who associate restrictive clauses with that. But why is the sentence confusing because of the original use of which? For those writers who use that and which interchangeably, the sentence would be restrictive no matter which of the two relative pronouns were selected.. Bernstein seems so consumed with converting all whichs to thats in restrictive adjectival clauses that he finds problems where none seems to exist.

Much of this discussion about the use of that and which in restrictive clauses is based on the differences between grammar and rhetoric. There is clearly no grammatical rule of any sort that claims that that should be selected over which in restrictive clauses. Grammarians are free to instruct students with grammatical impunity as to the interchangeability of that and which in restrictive clauses. There does, however, appear to be a not-so-tacit yearning to select exclusively that for restrictive clauses when viewed from a rhetorical point of view as expressed in Fowler, Bernstein, and Crews, three distinguished spokespersons for the English language. Grammar versus rhetoric? Which should hold sway? We quote Bernstein:

\footnotetext{
The preference expressed here for the use of that for the defining clause and which for the nondefining does not rest so much on any ground of clarity, however, as on the ground of doing what comes naturally. Oddly enough, despite ample evidence that the relative that is preferred for the defining clause by speakers of the language, the structural linguisticians, who normally contend that the spoken language is the language, and who set great store by counts of mass noses, take up no cudgels in this cause. They are perfectly free, of course, to use that and which indiscriminately. No one ventures to lay down a rule on the subject, not even Fowler-he merely expresses a wistful wish. Yet it is all very curious. (Bernstein 1981: 445)
}

How, therefore, are we to instruct students in our writing classes? There is, of course, the injunction to use which and not that in nonrestrictive clauses. No one wants to quibble with this hard and fast rule. Should we, however, following Watkins and Dillingham, Frodesen and Eyring, Crowel, and Azar, instruct our students, as so many teachers do, that that and which are interchangeable in restrictive clauses? Or should we inform them, following Bernstein, Crews, and Fowler, that these issues are much more complicated than that happy assertion implies and that, from hereon, students should be taught that that is used only for restrictive clauses and which for nonrestrictive ones and that never the twain shall meet? Students love rules and while rules, as the old adage insists, were meant to be broken, our students tend to be faithful and loyal subjects who break only their pencils when writing compositions. Yet Bernstein acts as if the rule has already been established when he writes: 
Let it be noted that there are two exceptions to the use of that to introduce a defining clause. One is a situation in which the demonstrative that and the relative that come together, as in this sentence: 'The latent opposition to rearming Germany is as strong as that that has found public expression.'

Idiom dictates making it that which, the second exception is a situation in which the relative follows a preposition; for example, of which, not of that. (Bernstein 1981: 446)

The exceptions have been duly noted. But who ever claimed there was such a rule, much less exceptions? Indeed, if it is a rule, then a good many rhetoric teachers and grammarians around the world would be willfully ignorant of their errors.

We will leave the matter as vague and ambiguous as we found it. That the controversy over that and which in restrictive clauses rages somewhere down beneath the quaint and simple level of basic rhetoric books has also been duly noted, and we should all be aware of its existence. That this controversy can be easily resolved is still another matter altogether.

The argument, however, for the exclusive use of that in restrictive clause seems to us somewhat flimsy at best and forced at worst. Is there really any confusion created by the interchangeability of these words? Perhaps. And life might well be easier in the classroom and on the page by limiting that to restrictive and which to nonrestrictive clauses. Like the use of commas, this marker would be still another way to set off and indicate to the reader which of the two adjectival relative clauses was intended, restrictive or nonrestrictive. But some might claim that such an argument is based on redundancy given that commas are meant precisely for that purpose: to set off nonrestrictive clauses. The absence of commas signals to the reader a restrictive clause regardless of which of the two relative pronouns at any one time might be chosen, and no additional marker for a restrictive clause is needed; indeed, any other marker such as limiting that to restrictive clauses might well be considered redundant. The comma already performs that signaling task, both in its presence and in its absence: restrictive clauses do not take commas, nonrestrictive do.

But since life is much simpler with rules, shall we then bow to the higher wisdom of Fowler and Bernstein whose case is made, it seems to us, not for the sake of any sense of clarity but merely for the sake of the clarion call that signals the arrival of the restrictive clause? Like Roland's horn, That announces to the reader the restrictive clause, and, while the absence of commas has exactly the same function, one assumes that two horns are better than one, and the readers can not but feel consoled that, when they encounter which, they will shortly thereafter meet only a nonrestrictive clause and that that will usher them into the presence of a restrictive one.

\section{Note}

1. Or is there? It is curious to note that in the next sentence, Onions himself writes: "to give some additional information about an antecedent which is already sufficiently defined." (emphasis ours). Here Onions seems to violate what he had just stated concerning the exclusive use of that in relative clauses. He uses which in his own example, and as readers we can only be nonplussed and somewhat baffled by his apparent capricious use of which for that. On the one hand, Onions instructs us to use that for restrictive clauses, but then in his own next sentence it seems that he holds the position of many grammarians (as cited above) in regards to the interchangeability of that and which in restrictive clauses. 


\section{References}

Azar, Betty S. 1989. Understanding and Using English Grammar. New Jersey: Prentice Hall.

Bernstein, Theodore. 1981. The Careful Writer: A Modern Guide to English Usage. New York: Atheneum.

Crews, Fredrick. 1974. The Random House Handbook. New York: Random House.

Crowel. 1964. Index to Modern English. New York: McGraw Hill Book Company.

Flores, Berta, et al. 2002. Basic English Syntax. San José: Editorial de la Universidad de Costa Rica.

Fowler, W. H. 1977. A Dictionary of Modern English Usage. Oxford: Oxford University Press.

Feigenbaum, Irwin. 1985. The Grammar Handbook. New York: Oxford University Press.

Frodesen, Jan and Janet Eyring. 1994. Grammar Dimensions. Boston: Heinle and Heinle.

Howell, James F. and Dean Memering. 1996. Brief Handbook for Writers. Englewood Cliffs: Prentice Hall.

Karls, John B. and Ronald Symanski. 1994. The Writer's Handbook: A Guide to the Essentials of Good Writing. Lincolnwood: National Textbook Company.

Leech, Geoffrey and Jan Svartvik. 1975. A Communicative Grammar of English. Hong Kong: Longman Group Ltd.

Mauer, Jay. 2000. Focus on Grammar. New York: Addison Wesley Longman, Inc.

Onions, C.T. 1965. An Advanced English Syntax: Based on the Principles and Requirements of the Grammatical Society. London: Routledge and Kegan Paul.

Partridge, Eric. 1947. Abusage and Usage. New York: Penguin Books.

Raines, Ann. 1983. Techniques in Teaching Writing. Oxford: Oxford University Press.

Watkins and Dillingham. 1986. Practical English Handbook. Boston: Houghton Mifflin Company. 